\title{
Pai syndrome
}

INSERM

\section{Source}

INSERM. (1999). Orphanet: an online rare disease and orphan drug data base. Pai syndrome. ORPHA:1993

Pai syndrome is an idiopathic developmental disorder characterized by median cleft of the upper lip (MCL), midline polyps of the facial skin and nasal mucosa, and pericallosal lipomas. Hypertelorism with ocular anomalies are also observed, generally with normal neuropsychological development. 